Systematic Review

\title{
Comparison of Clinical Efficacy Between Transforaminal and Interlaminar Epidural Injections in Lumbosacral Disc Herniation: A Systematic Review and Meta-Analysis
}

\author{
Jung Hwan Lee, MD, PhD', Kyoung-ho Shin, MD², Sung Jin Park, MD³, Goo Joo Lee, MD, \\ Chang-Hyung Lee, MD, PhD ${ }^{5}$, Dong Hwan Kim, MD, PhD ${ }^{6}$, Du Hwan Kim, MD, PhD7, \\ and Hee Seung Yang, MD ${ }^{8}$
}

From: ${ }^{1}$ Department of Physical and Rehabilitation Medicine, Spine Health Wooridul Hospital, Seoul, South Korea; ${ }^{2} \mathrm{Heal} \&$ Teun Rehabilitation \& Pain Clinic, Bundang, South Korea; ${ }^{3}$ Seocho Se Barun Hospital, Seoul, South Korea; ${ }^{4}$ Chungbuk National University Hospital, Department of Physical and Rehabilitation Medicine, Cheongjoo, South Korea; ${ }^{5}$ Department of Physical and Rehabilitation Medicine,

Pusan National University Yangsan Hospital, School of Medicine, Pusan National University, Yangsan, South Korea; ${ }^{6}$ Department of Physical and Rehabilitation Medicine, College of Medicine, Kyung Hee University Hospital, Seoul, South Korea; ${ }^{7}$ Department of Physical and Rehabilitation Medicine, Dongsan Medical Center, School of Medicine, Keimyung University; Daegu, South Korea; ${ }^{8}$ Department of Physical and Rehabilitation Medicine, Veterans Medical Center, Seoul, South Korea

Address Correspondence: Jung Hwan Lee, MD PhD

Department of Physical and Rehabilitation Medicine Spine Health Wooridul Hospital 445, Hakdong-ro, Gangnam-gu, Seoul, South

E-mail:j986802@hanmail.net

Conflict of interest: See P. 451.

Manuscript received: 02-26-2018 Revised manuscript received: 04-04-2018

Accepted for publication: 05-16-2018

Free full manuscript: www.painphysicianjournal.com
Background: Epidural injection (EI) is used to treat back or radicular pain from lumbosacral disc herniation (LDH). Although several reports have stated that the transforaminal approach in El (TFEI) has an advantage in target specificity and yields better clinical efficacy than the interlaminar approach in El (ILEI), other studies have indicated that the clinical efficacy of ILEI was not inferior to that of TFEI and that ILEI also has the ability to spread medication into the ventral space to a degree similar to that of TFEI. There has been controversy about whether TFEI is superior to ILEI in clinical efficacy.

Objectives: This systematic review and meta-analysis aimed to investigate whether TFEl is more useful than ILEI for achieving clinical outcomes in patients with LDH.

Study design: A systematic review and meta-analysis using a random effects model on randomized controlled studies (RCT).

Methods: A literature search was performed in MEDLINE, EMBASE, Cochrane review, and KoreaMed for studies published from January 1996 until July 2017. From those found fulfilling the search criteria, manuscripts that compared the clinical efficacy of steroids and control agents, such as local anesthetics or saline, in terms of pain control and functional improvement were included in this study. Exclusion criteria included a previous history of lumbosacral surgery, nonspecific low back pain, severe spinal stenosis, and severe disc degeneration. After reviewing titles, abstracts, and the full text of 6,711 studies; 12 studies were included in the qualitative synthesis. Data including pain scores, functional scores, and follow-up period were extracted from 10 studies and analyzed using a random effects model to obtain effect size and its statistical significance. The quality and level of evidence were analyzed in accordance with the Grading of Recommendations Assessment, Development and Evaluation (GRADE) methodology.

Results: In terms of pain control, TFEl showed significantly better short-term (2 weeks to 1 month) outcomes and slightly favorable long-term (4 - 6 month) outcomes, but without significance, in comparison with ILEI. In terms of functional improvement, TFEI also showed favorable short- and long-term outcomes, but without significance, in comparison with ILEI. TFEI had target specificity, required no additional cost and resources, and had equal applicability to ILEl. However, TFEI was more associated with a higher frequency of discomfort or adverse events during the procedure. Overall, better results were reported with TFEI over ILEI, but with low-grade evidence due to the inconsistency and imprecision of the selected studies.

Limitation: Analyses of safety or adverse effects could not be performed due to a lack of available data from the included studies.

Conclusions: Based on low-grade evidence, TFEl showed significantly better short-term pain control and slightly favorable outcomes in long-term pain reduction and short- and long-term functional improvement in comparison with ILEI.

Key words: Epidural injection, interlaminar, transforaminal, meta-analysis, systemic review, pain, function

Pain Physician 2018: 21:433-447 
umbar epidural injections (EI) have been used to treat low back and lower extremity pain from lumbosacral disc herniation (LDH) $(1,2)$. The epidural administration of the drugs provides targeted delivery of the medications and supresses inflammatory mediators that irritate nervous tissues. Three types of techniques such as interlaminar (ILEI), caudal, and transforaminal epidural injection (TFEI) have been utilized in clinical practice. Because axial back or radicular leg pain is mainly generated from sinuvertebral nerves existing in the ventral epidural space, the nerve root sheath and the dorsal root ganglion, the main target of drug administration is logically considered the ventral epidural spread rather than the dorsal epidural space $(3,4)$. Hence, TFEI is preferred by some physicians because it delivers the medication directly into the ventral epidural space (5-8), whereas, ILEI delivers the medication into the posterior epidural spaces under the expectation that the administered medication ideally spreads to the ventral spaces afterward (9-12).

Even though several reports have stated that TFEI obtained better clinical efficacy than ILEI in patients with $\operatorname{LDH}(9,13-16)$, conflicting studies have indicated that the clinical efficacy of ILEI was not inferior to that of TFEI and that it also had the ability to spread the medication into the ventral space to a degree similar to that of TFEI (16-20). Furthermore, one study found that ILEI involved less pain or discomfort, and that it was less likely than TFEI to penetrate vascular structures during needle insertion (18).

One systemic review compared the clinical efficacy between TFEI and ILEI. This review concluded that there was no significant difference found between the 2 methods (16). Another systemic review comparing caudal, lumbar interlaminar, and transforaminal approach techniques indicated that all methods conducted under fluoroscopic guidance were effective at managing lumbar disc herniation in terms of pain relief and functional improvement (21). However, the authors did not perform a meta-analysis comparing TFEI and ILEI. Identifying which method is more clinically useful could help physicians choose appropriate treatments for patients with LDH. Thus, this systematic review and meta-analysis investigates whether TFEl is more useful than ILEI in terms of pain control and functional improvement during short- and long-term follow-up in the treatment of patients with LDH during short- and long-term follow up periods.

\section{Methods}

\section{Study Selection Criteria}

We included articles with human subjects written in Korean or English that met the following criteria: patients aged $\geq 18$ years, clinical presentation of low back and radicular leg pain, diagnosis of LDH on a radiological evaluation such as computed tomography or magnetic resonance imaging. Exclusion criteria included a previous history of lumbosacral surgery, nonspecific low back pain without a definite diagnosis of $\mathrm{LDH}$ on radiological evaluation, spinal stenosis, severe disc degeneration, intradiscal disc derangement or a bulging disc, or prominent spinal instability. Of the studies fulfilling these criteria, those that compared the clinical efficacy of TFEI and ILEI in terms of pain control and functional improvement under C-arm fluoroscopy were included in the present study.

\section{Database Search and Study Extraction}

The MEDLINE (Pubmed), EMBASE, Cochrane review, and KoreaMed databases were searched for articles published up to July 2017. We established individual search terms in each database's search engine (Appendix). The search was not restricted to randomized controlled studies (RCT) and was extended to original articles, including non-RCT. The decision to include an article was primarily made based on title and abstract review, followed by fulltext screening. The study screening and data extraction were independently performed by 2 reviewers, and any discrepancies were resolved by discussion between the 2 reviewers or with the entire research group.

\section{Data Collection}

Reference data such as the number of subjects, type and dose of injected medication, follow-up period, clinical evaluation tools, and comparative results of the clinical outcomes were extracted from the selected articles. Dichotomous variables such as the number of patients with successful clinical outcomes were extracted for the estimation of relative risk ratio and continuous variables such as mean and standard deviation of pain and functional scores were extracted for the estimation of mean differences. If standard deviations were not reported, they were calculated from confidence intervals, mean, and the number of patients. 


\section{Quality Assessment of Selected Studies, Establishment of Level of Evidence, and Strength of Recommendation}

Quality assessment of each study and level of evidence was established in accordance with the Grading of Recommendations Assessment, Development and Evaluation (GRADE) methodology (22). The bias assessment for each RCT was conducted by method of risk of bias (ROB), which consisted of 7 domains: random sequence generation, allocation sequence concealment, blinding of participants and personnel, blinding of outcome assessment, incomplete outcome data, selective outcome reporting, and other biases. The bias for each non-RCT was assessed by Risk of Bias Assessment tool for Non-randomized Study (RoBANs), domains of which were selection of participants, confounding variables, intervention (exposure) measurements, blinding outcome assessment, incomplete outcome data, selective outcome reporting, and other biases. All the domains were evaluated with "low risk," "high risk," or "unclear." These evaluations were performed by 2 independent reviewers and disagreements were resolved by discussion between the 2 reviewers or with the whole research group.

The components of inconsistency, indirectness, imprecision, and publication bias were comprehensively examined in addition to the risk of bias of all studies. Evidence level was determined as high, moderate, low, or very low grades. The strength of recommendation was determined as strong or weak by comprehensively assessing not only evidence level, but also other factors such as balancing benefits and harms, resources required, values and preferences, and acceptability/ feasibility (22). The level of evidence and strength of recommendation were determined by discussion by the entire research group.

Quality assessment was performed using the Cochrane review criteria and Interventional Pain Management techniques Quality Appraisal of Reliability and Risk of Bias Assessment (IPM-QRB). Studies meeting the inclusion criteria with a Cochrane review score of 8-12 were considered high quality with respect to the Cochrane criteria; those with a score of 4-7 were considered moderate-quality; and those with a score less than 4 were considered low-quality. Studies meeting the inclusion criteria with an IPM-QRB score of 32-48 were considered high quality with respect to the IPM-QRB criteria; those with a score of 16-31 were considered moderate quality; and those with a score less than 16 were considered low-quality (23-26). Only high- and moderate-quality studies were included in the present review.

\section{Meta-analysis}

Review Manager software (RevMan version 5.3; The Cochrane Collaboration 2014) was used for data analysis. The analysis was done in 4 categories of pain control and functional improvement at short- and long-term follow-up period. Tests of heterogeneity were performed using 12 statistics. The category with 12 values of $50 \%$ or more was considered to have a high degree of heterogeneity and was assessed again by subgroup analysis. A random effect model was applied to obtain effect size and its statistical significance because it was assumed that the subjects and methods of included studies performed by independent researchers could not be entirely equivalent and, therefore, could not have a common effect size. A probability of $P<0.05$ was considered statistically significant. The results were expressed as mean difference and $95 \%$ confidence interval $(95 \% \mathrm{Cl})$ for continuous outcome data and in the form of relative risk ratio and $95 \% \mathrm{Cl}$ for dichotomous outcome data.

\section{Results}

\section{Search Results}

Our database search initially yielded 9,088 articles. After the removal of 2,377 duplicates, 6,711 potentially eligible articles remained. After title and abstract screening, 6,407 articles were excluded because they did not meet the inclusion criteria. Thus, 304 articles were retrieved for full-text analysis, of which 292 were subsequently excluded because they were irrelevant to this study. Ultimately, 10 RCT and 2 non-RCT (prospective observational studies) were included in this study. The pain intensity measures used in the selected studies were the visual analog scale (VAS) or the numerical rating scale (NRS). Both scores were considered the same in the meta-analysis because they were highly correlated and, when transformed, could be used interchangeably (27). The most frequently used functional measurement tool used in the selected studies was the Oswestry Disability Index (ODI). However, one study (15) provided only the Japan Orthopedic Association score as a functional evaluation that could not be correlated with ODI; thus, it was excluded from the meta-analysis. Because another RCT did not provide available data for the meta-analysis (28), 10 studies (7 RCTs and 3 nonRCTs) were ultimately included in the meta-analysis. 
Figure 1 demonstrates a flowchart of the study selection process. The follow-up period was variable across the studies ranging from 1 day to 1 year. The short-term follow-up period was 2 weeks to 1 month, while the long-term follow-up period was 4 to 6 months because pain and functional data in this period could be most abundantly obtained and clinically meaningful. Clinical data after 6 months was not considered due to clinical effects from previously performed ESI deteriorating substantially by this time $(2,29)$.

\section{Quality Assessment}

The risk of bias of all selected studies is illustrated in Fig. 2 ( $a$ : RCT, b: non-RCT). Except for one RCT that was assessed as high risk, all RCTs were assessed as low risk in the random sequence domain (30). The domain that was most frequently biased was allocation concealment, of which 5 RCTs were rated as unclear because they did not adequately describe the procedure for allocation concealment $(3,13,20,30,31)$, and 2 RCTs were graded as high risk because they showed flaws in the

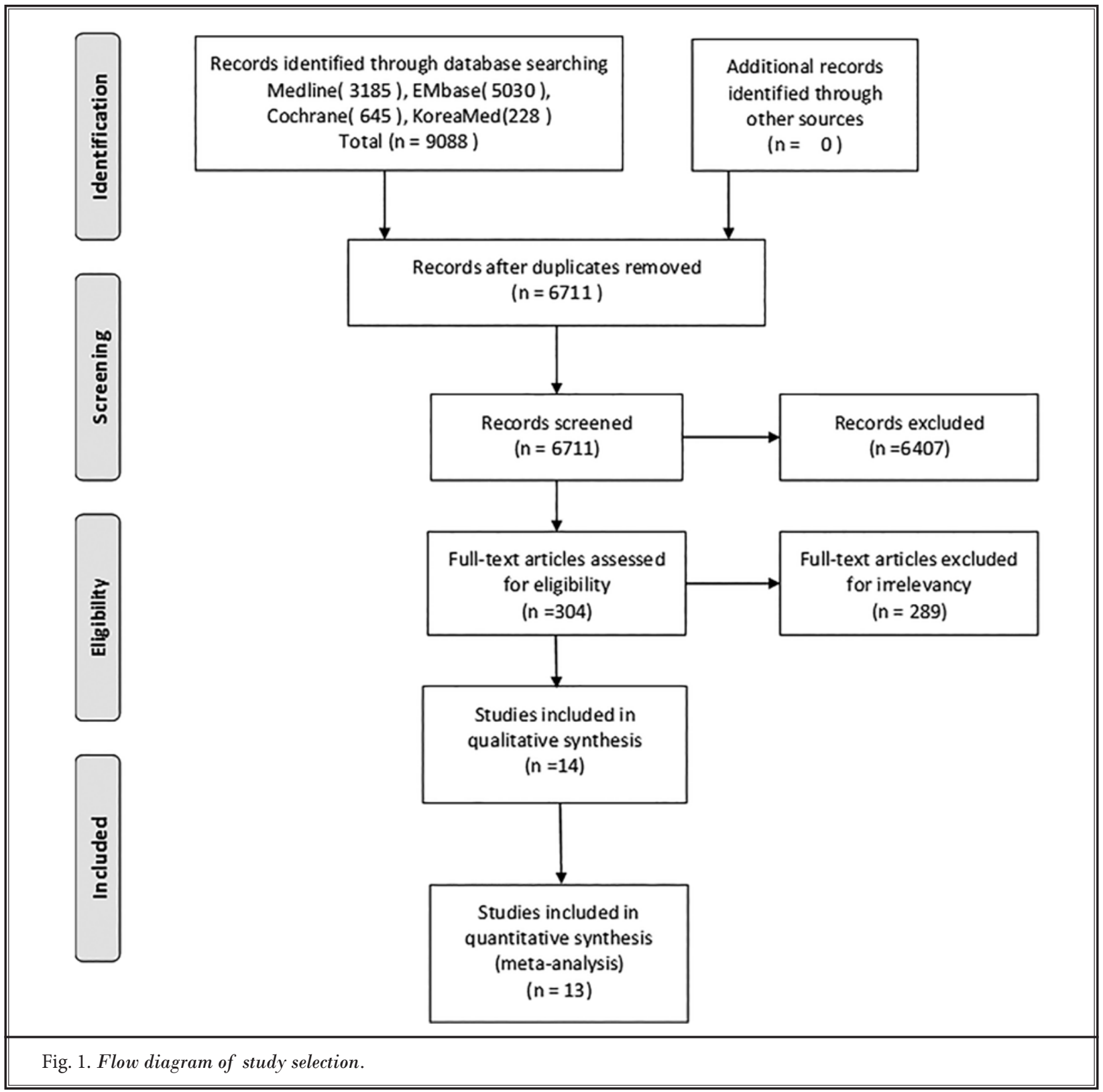


(a)

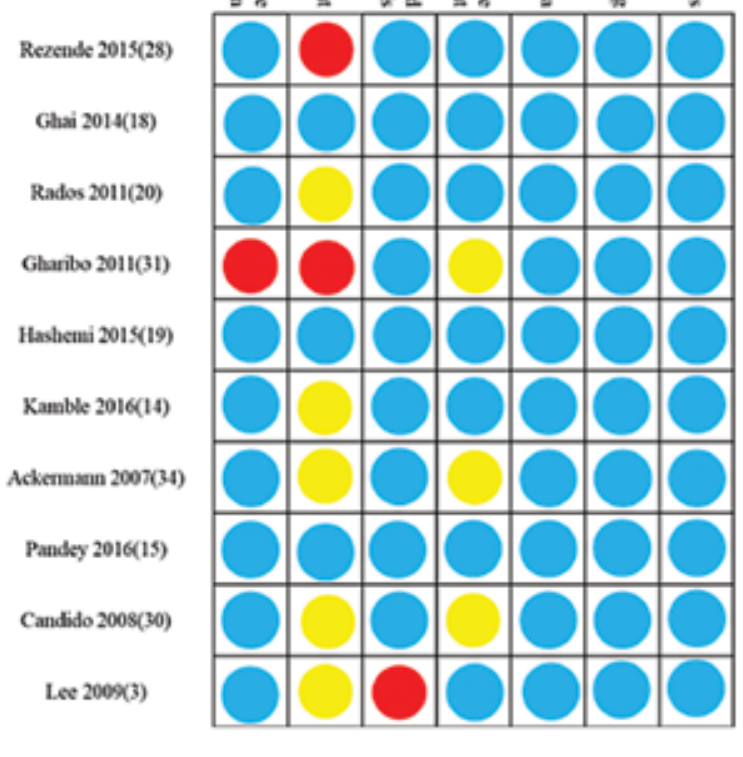

(b)

Blue: low risk of bias

Red: high risk of bias

Yellow: unclear risk of bias

Fig. 2. Quality assessment for extracted studies a) risk of bias(ROB) for randomized controlled study, b) Risk of Bias Assessment tool for Non-randomized Study (RoBANs) for non-randomized study.

allocation process $(15,28)$. One of the non-RCTs was rated as unclear in the domain of confounding variables because it did not clearly present the procedures of excluding the confounding factors $(17,32,33)$. Of 84 domains across all studies, 69 domains (82.1\%) were determined as low risk; thus, the overall risk of bias was considered low.

\section{Clinical Outcome Analysis}

Among the 10 RCTs ultimately selected, no significant difference of clinical efficacy was found between TFEI and ILEI in 5 studies $(3,18-20,31)$, another 4 reported $(14,15,28,34)$ that TFEI obtained significantly better clinical effects than ILEI during 3-12 months follow-up periods, and 1 article (30) noted that TFEI was more effective in the short term but the superiority was diminished after 2 weeks. Between the 2 non-RCTs, one study (17) showed no significant difference between the 2 techniques, and the other study (9) stated that TFEI demonstrated better clinical efficacy than ILEI). Comprehensively, TFEI was non-inferior or superior to
ILEI in the treatment of patients with LDH (Table 1).

Quality assessment results of the Cochrane review criteria and IPM-QRB for RCTs and IPM-QRBNR for nonRCTs are presented in Tables 2, 3 and 4 respectively. All RCTs were rated as high quality for Cochrane review criteria, with 7 RCTs determined as high and 3 RCTs as moderate quality according to IPM-QRB. One non-RCT was rated as high quality and the other non-RCT was rated as moderate.

\section{Pain Control in the Short-Term Period (2 Weeks to 1 Month)}

Three studies $(3,18,19)$ reported the number of patients with successful pain reduction in the short-term period after TFEI, thus enabling the measurement of effect size by the relative risk ratio of successful pain control in the short-term period. Overall, 83 of 121 cases treated with TFEI and 71 of 98 cases treated with ILEI accomplished successful pain reduction. Although no statistically significant difference between TFEI and ILEI was found $(P=0.60)$, the data showed slightly 
Table 1. Summary of studies included in this study.

\begin{tabular}{|c|c|c|c|c|c|}
\hline 1st author & TFESI & ILESI & Evaluation & Follow up & outcomes \\
\hline \multicolumn{6}{|l|}{ RCT } \\
\hline Rezende 2015 (28) & $\begin{array}{l}\mathrm{N}=20 \\
3 \mathrm{~mL} \text { of betamethasone } \\
\text { phosphate }(40 \mathrm{mg} / \mathrm{mL}) 2 \mathrm{~mL} \text { of } \\
0.25 \% \text { neo-bupivacaine } 5 \mathrm{~mL} \text { of } \\
\text { distilled water }\end{array}$ & $\begin{array}{l}\mathrm{N}=20 \\
3 \mathrm{~mL} \text { of betamethasone } \\
\text { phosphate }(40 \mathrm{mg} / \mathrm{mL}) 2 \mathrm{~mL} \\
\text { of } 0.25 \% \text { neo-bupivacaine } 5 \\
\mathrm{~mL} \text { of distilled water }\end{array}$ & VAS & $\begin{array}{l}1 \text { day to } 3 \\
\text { months }\end{array}$ & TFESI $>>$ ILESI \\
\hline Ghai 2014 (18) & $\begin{array}{l}\mathrm{N}=30 \\
2 \mathrm{~mL} \text { of methylprednisolone } \\
\text { acetate }(40 \mathrm{mg} / \mathrm{mL}) 2 \mathrm{~mL} \text { of sterile } \\
\text { normal saline }\end{array}$ & $\begin{array}{l}\mathrm{N}=32 \\
2 \mathrm{~mL} \text { of methylprednisolone } \\
\text { acetate }(40 \mathrm{mg} / \mathrm{mL}), 2 \mathrm{~mL} \text { of } \\
\text { sterile normal saline }\end{array}$ & VAS, MODQ & $\begin{array}{l}2 \text { weeks to } 12 \\
\text { months }\end{array}$ & $\begin{array}{l}\text { no significant } \\
\text { difference }\end{array}$ \\
\hline Rados 2011 (20) & $\begin{array}{l}\mathrm{N}=32 \\
40 \mathrm{mg} \text { of methylprednisolone, } 3 \\
\mathrm{~mL} \text { of } 0.5 \% \text { lidocaine }\end{array}$ & $\begin{array}{l}\mathrm{N}=32 \\
80 \mathrm{mg} \text { of methylprednisolone } \\
8 \mathrm{~mL} \text { of } 0.5 \% \text { lidocaine }\end{array}$ & VAS, ODI & 6 months & $\begin{array}{l}\text { no significant } \\
\text { difference }\end{array}$ \\
\hline Gharibo 2011 (31) & $\begin{array}{l}\mathrm{N}=20 \\
40 \mathrm{mg} \text { of triamcinolone }(40 \mathrm{mg} / \\
\mathrm{mL}) 1 \mathrm{~mL} \text { of } 0.25 \% \text { bupivacaine }\end{array}$ & $\begin{array}{l}\mathrm{N}=18 \\
80 \mathrm{mg} \text { of triamcinolone } 2 \mathrm{~mL} \\
\text { of } 0.25 \% \text { bupivacaine }\end{array}$ & $\begin{array}{l}\text { NRS,ODI } \\
\text { depression } \\
\text { scale walking } \\
\text { tolerance }\end{array}$ & $2-3$ weeks & $\begin{array}{l}\text { TFESI }>>\text { ILESI at } \\
\text { initial stage, but } \\
\text { no significant } \\
\text { difference at } \\
\text { subacute stage } \\
\end{array}$ \\
\hline Hashemi 2015 (19) & $\begin{array}{l}\mathrm{N}=32 \\
2 \mathrm{~mL} \text { of triamcinolone } 2 \mathrm{~mL} \\
\text { of bupivacaine } 6 \mathrm{~mL} \text { of sterile } \\
\text { normal saline }\end{array}$ & $\begin{array}{l}\mathrm{N}=32 \\
2 \mathrm{~mL} \text { of triamcinolone } 2 \mathrm{~mL} \\
\text { of bupivacaine } 6 \mathrm{~mL} \text { of sterile } \\
\text { normal saline }\end{array}$ & NRS,ODI & 4 weeks & $\begin{array}{l}\text { no significant } \\
\text { difference }\end{array}$ \\
\hline Kamble 2016 (14) & $\begin{array}{l}\mathrm{N}=30 \\
40 \mathrm{mg} \text { of triamcinolone acetate } \\
1 \mathrm{~mL} \text { of bupivacaine } 2 \mathrm{~mL} \text { of } \\
\text { lignocaine }\end{array}$ & $\begin{array}{l}\mathrm{N}=30 \\
40 \mathrm{mg} \text { of triamcinolone } \\
\text { acetate } 1 \mathrm{~mL} \text { of bupivacaine } \\
1 \mathrm{~mL} \text { of lignocaine } 10 \mathrm{~mL} \text { of } \\
\text { normal saline }\end{array}$ & VAS, ODI & 1,6 months & TFESI > ILESI \\
\hline $\begin{array}{l}\text { Ackermann } 2007 \\
\text { (34) }\end{array}$ & $\begin{array}{l}\mathrm{N}=30 \\
40 \mathrm{mg} \text { of triamcinolone } 4 \mathrm{~mL} \text { of } \\
\text { normal saline }\end{array}$ & $\begin{array}{l}\mathrm{n}=30 \\
40 \mathrm{mg} \text { of triamcinolone } 4 \mathrm{~mL} \\
\text { of normal saline }\end{array}$ & $\begin{array}{l}\text { VAS OLBPS } \\
\text { BDI, NPIS }\end{array}$ & 6 months & TFESI > ILESI \\
\hline Pandey 2016 (15) & $\begin{array}{l}\mathrm{N}=40 \\
1 \mathrm{~mL} \text { of } 2 \% \text { xylocaine } 40 \mathrm{mg} \text { of } \\
\text { methylprednisolone. }\end{array}$ & $\begin{array}{l}\mathrm{N}=18 \\
4 \mathrm{~mL} \text { of } 2 \% \text { xylocaine } 40 \mathrm{mg} \text { of } \\
\text { methylprednisolone }\end{array}$ & JOA & $\begin{array}{l}6 \text { months, } 1 \\
\text { year }\end{array}$ & TFESI > ILESI \\
\hline Candido 2008 (30) & $\begin{array}{l}\mathrm{N}=28 \\
80 \mathrm{mg} \text { of methylprednisolone } \\
\text { acetate } 1 \mathrm{~mL} \text { of normal saline } 1 \\
\mathrm{~mL} \text { of } 1 \% \text { lidocaine }\end{array}$ & $\begin{array}{l}\mathrm{N}=29 \\
80 \mathrm{mg} \text { of methylprednisolone } \\
\text { acetate } 1 \mathrm{~mL} \text { of normal saline } \\
1 \mathrm{~mL} \text { of } 1 \% \text { lidocaine }\end{array}$ & VAS & $\begin{array}{l}2 \text { weeks to } 6 \\
\text { months }\end{array}$ & $\begin{array}{l}\text { no significant } \\
\text { difference }\end{array}$ \\
\hline Lee 2009 (3) & $\begin{array}{l}\mathrm{N}=59 \\
40 \mathrm{mg} \text { of triamcinolone } 8 \mathrm{~mL} \text { of } \\
0.5 \% \text { lidocaine }\end{array}$ & $\begin{array}{l}\mathrm{N}=34 \\
40 \mathrm{mg} \text { of triamcinolone } 8 \mathrm{~mL} \\
\text { of } 0.5 \% \text { lidocaine }\end{array}$ & $\begin{array}{l}\text { NRS, PSI } \\
\text { Roland } 5 \\
\text { points scale }\end{array}$ & $\begin{array}{l}2 \text { weeks to } 4 \\
\text { months }\end{array}$ & $\begin{array}{l}\text { no significant } \\
\text { difference }\end{array}$ \\
\hline \multicolumn{6}{|l|}{ Non RCT } \\
\hline $\begin{array}{l}\text { Manchikanti } 2015 \\
\text { (17) }\end{array}$ & $\begin{array}{l}\mathrm{N}=1201.5 \mathrm{~mL} \text { of } 1 \% \text { lidocaine } \\
\text { with } 0.5 \mathrm{~mL} \text { of sodium } \\
\text { chloride solution or } 3 \mathrm{mg} \text { of } \\
\text { betamethasone }\end{array}$ & $\begin{array}{l}\mathrm{N}=1206 \mathrm{~mL} \text { of } 0.5 \% \text { lidocaine } \\
\text { or } 5 \mathrm{ml} \text { of lidocaine with } 1 \\
\mathrm{~mL} \text { of steroid }\end{array}$ & NRS, ODI & $\begin{array}{l}3 \text { to } 24 \\
\text { months }\end{array}$ & $\begin{array}{l}\text { no significant } \\
\text { difference }\end{array}$ \\
\hline Schaufele 2006 (9) & $\begin{array}{l}\mathrm{N}=2080 \mathrm{mg} \text { of } \\
\text { methylprednisolone } 1-2 \mathrm{~mL} \text { of } \\
2 \% \text { lidocaine }\end{array}$ & $\begin{array}{l}\mathrm{N}=2080 \mathrm{mg} \text { of } \\
\text { methylprednisolone } 2-3 \mathrm{~mL} \\
\text { of } 2 \% \text { lidocaine }\end{array}$ & NRS & $\begin{array}{l}1 \text { hours to } 2-3 \\
\text { weeks }\end{array}$ & TFESI > ILESI \\
\hline
\end{tabular}

TFESI : transforaminal epidural steroid injection, ILESI : interlaminar epidural steroid injection

VAS : visual analogue scale, MODQ : modified oswestry disability questionnaire, ODI : oswestry disability score

NRS : numeric rating scale, OLBPS : Oswestry low back pain scale, BDI : Back depression index,

NPIS : Numeric pain intensity score, JOA : Japanese Orthopaedic Association 
favorable trends toward ILEI with an estimated relative risk ratio of $0.95(95 \%$ $\mathrm{Cl}$ : 0.80-1.14) (Fig. 3a). No heterogeneity was observed in dichotomous data analysis $\left(1^{2}=0 \%\right)$.

Four studies presented the continuous pain score data and were included in the analysis of effect size by mean difference $(9,14,30,31)$. The overall mean difference was measured as 1.04 $(95 \%$ Cl: $0.39-1.70)$ that supported the superiority of TFEl with statistical significance $(P=0.002)$ (Fig. 3b). A low degree of heterogeneity was observed in continuous data analysis $\left(I^{2}=29 \%\right)$.

\section{Pain Control in the Long-Term Period (4 to 6 Months)}

Five studies provided the number of patients with a successful pain score reduction at 4-6 months thus allowing for an estimate of relative risk ratio $(3,17,18,20,34)$. Successful pain reduction was found in 183 of the 273 patients who underwent TFEI versus 154 of the 250 patients who underwent ILEI. TFEI achieved a higher proportion of successful pain control than ILEI with an overall estimated effect size of 1.13 $(95 \% \mathrm{Cl}, 0.91-1.40)$ with no statistical significance $(P=0.29)$. A high degree of heterogeneity was found to be present $\left(I^{2}=58 \%\right)$.

A subgroup analysis was conducted after the division of the studies into 2 subgroups depending on whether ILEI used a higher steroid dosage or equal dosage of steroid to TFEl. Two studies $(17,20)$ in which ILEl used a higher steroid dose were included in the ILEl higher steroid dose group, while the 3 studies $(3,18,34)$ in which ILEI used an equal dose were included in the equal steroid dose subgroup. The equal steroid dose subgroup showed that TFEl had a better result than ILEI with an effect size of 1.43 (95\% Cl 1.02-1.99) with no degree of statistical significance but with a degree of clinical improvement $(P=0.09)(3,13,35)$. The level of heterogeneity was $I^{2}=58 \%$.

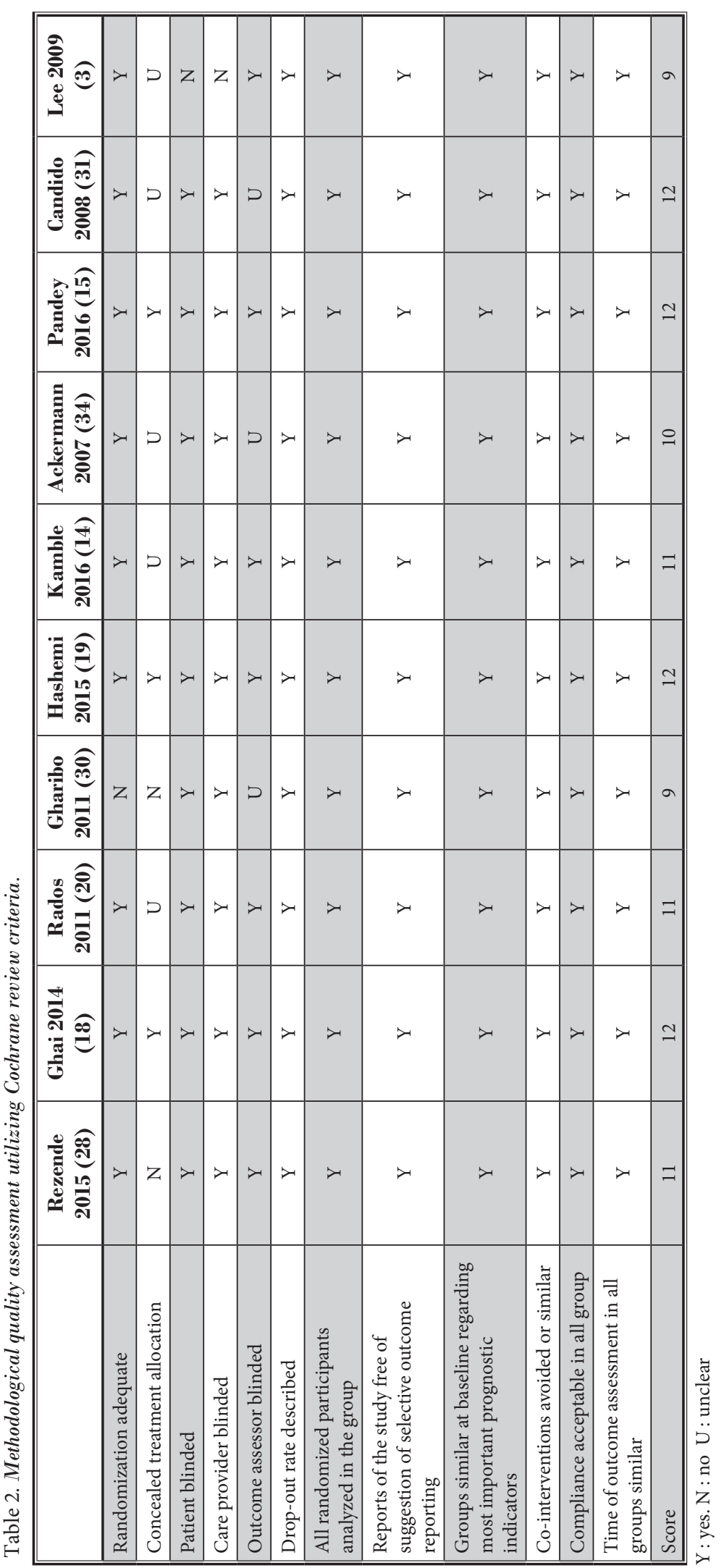




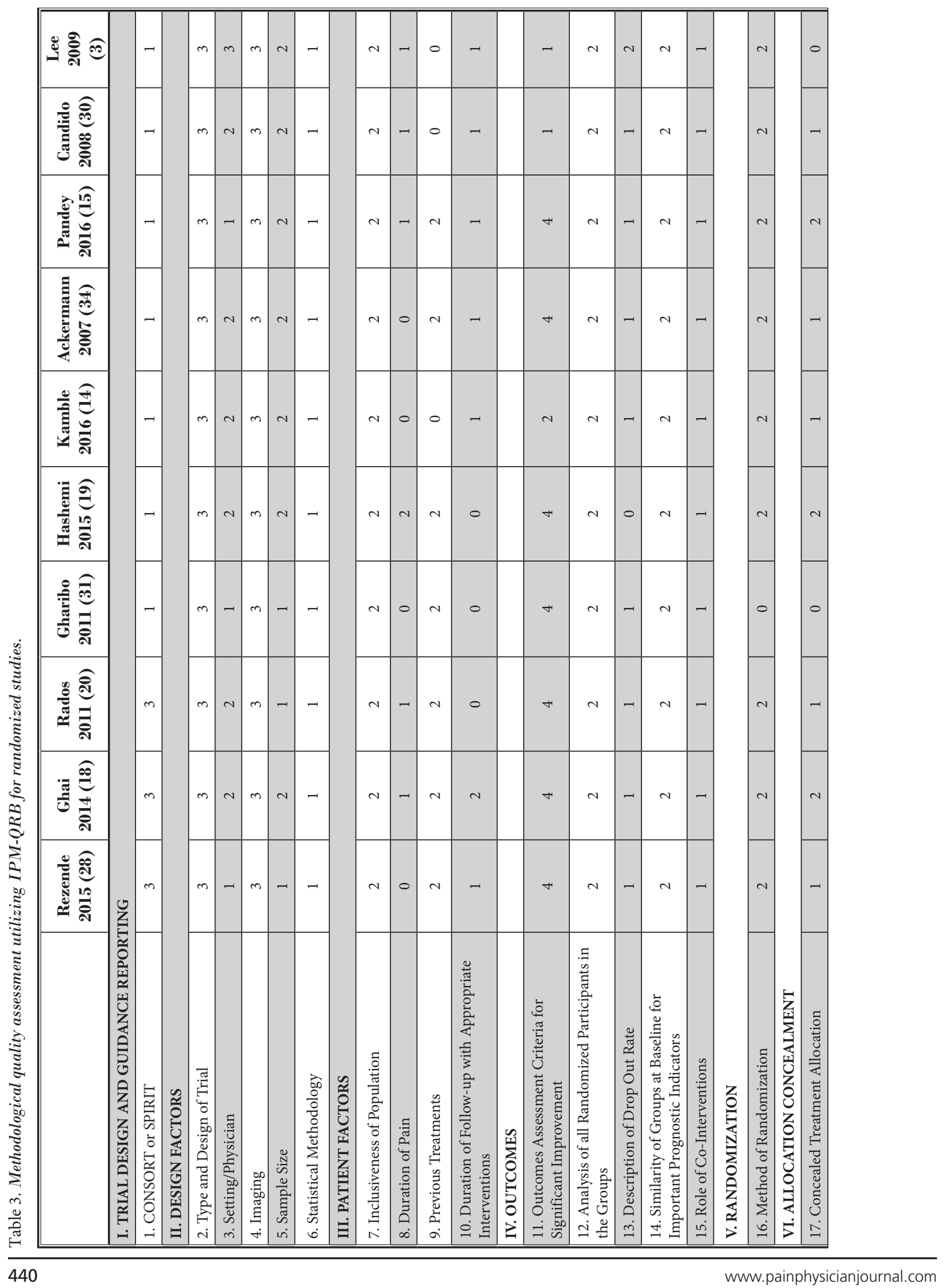


Transforaminal and Interlaminar Epidural Injection

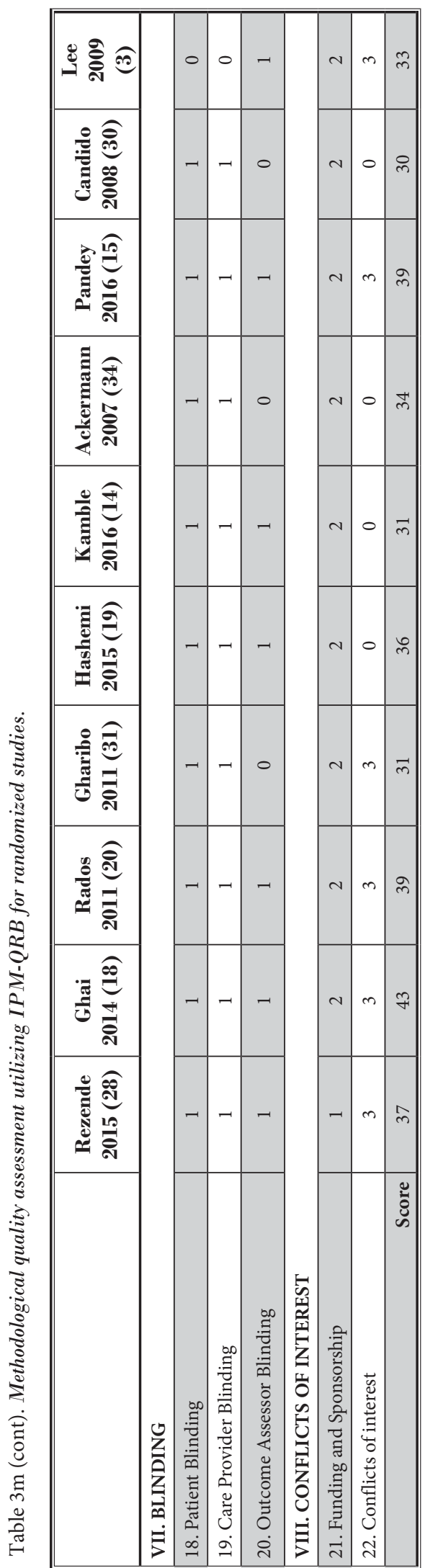

Table 4. Methodological quality assessment utilizing IPM-QRBNR for nonrandomized studies.

\begin{tabular}{|l|c|c||}
\hline & $\begin{array}{c}\text { Schaufele } \\
\text { 2006 (9) }\end{array}$ & $\begin{array}{c}\text { Manchikanti } \\
\text { 2015 (17) }\end{array}$ \\
\hline 1. Study Design Guidance and Reporting & 2 & 4 \\
\hline 2. Study Design and Type & 1 & 4 \\
\hline 3. Setting/Physician & 2 & 2 \\
\hline 4. Imaging & 3 & 3 \\
\hline 5. Sample Size & 0 & 4 \\
\hline 6. Statistical Methodology & 2 & 2 \\
\hline 7. Inclusiveness of Population & 4 & 4 \\
\hline 8. Duration of Pain & 0 & 2 \\
\hline 9. Previous Treatments & 2 & 0 \\
\hline $\begin{array}{l}\text { 10. Duration of Follow-up with Appropriate } \\
\text { Interventions }\end{array}$ & 1 & 4 \\
\hline $\begin{array}{l}\text { 11. Outcomes Assessment Criteria for Significant } \\
\text { Improvement }\end{array}$ & 1 & 0 \\
\hline 12. Description of Drop Out Rate & 0 & 2 \\
\hline $\begin{array}{l}\text { 13. Similarity of Groups at Baseline for Important } \\
\text { Prognostic Indicators }\end{array}$ & 2 & 2 \\
\hline 14. Role of Co-Interventions & 2 & 2 \\
\hline 15. Method of Assignment of Participants & 3 & 4 \\
\hline 16. Funding and Sponsorship & 27 & 2 \\
\hline & & 41 \\
\hline
\end{tabular}

The ILEI higher steroid dose subgroup, showed results supporting ILEI without statistical significance $(P=0.26)(17,20)$. Heterogeneity was reduced to $\mathrm{I}^{2}=22 \%$.

Continuous data of pain measurement scores were available in 4 studies $(14,17,20,31)$. The overall mean difference was calculated as $0.13(95 \% \mathrm{Cl}:-0.50-0,77)$ which favored TFEl, but this did not show statistical significance $(P=0.68)$. A high degree of heterogeneity was found $\left(I^{2}=70 \%\right)$ (Fig. $\left.3 d\right)$.

The subgroup analysis was conducted in the same way as the estimate of relative risk ratio. Two studies included in the ILEI higher steroid dose subgroup showed results that slightly favored ILEI by a mean difference of $-0.13(95 \% \mathrm{Cl}-0.43-0.16)$ with no statistical significance $(P=0.38)$. No heterogeneity was observed in this subgroup $\left(I^{2}=0 \%\right)(17,20)$. The equal steroid dose subgroup showed that TFEI showed better result than ILEI with an effect size of $0.66(95 \% \mathrm{Cl}$ $-0.15-1.47)$ that was without significance $(P=0.11)$. The level of heterogeneity was reduced to $I^{2}=31 \%(14,31)$.

\section{Functional Improvement in the Short-Term Period (2 weeks to 1 month)}

Only 2 studies $(14,30)$ presented continuous data consisting of functional scores at less than 1 month and were available in the analysis of effect size by mean difference. Although 2 studies 


\begin{tabular}{|c|c|c|c|c|c|c|c|c|c|c|}
\hline \multirow[b]{2}{*}{ Study or Subgroup } & \multicolumn{2}{|c|}{ Transforaminal } & \multicolumn{2}{|c|}{ Interlaminar } & \multirow{2}{*}{\multicolumn{2}{|c|}{$\begin{array}{c}\text { Risk Ratio } \\
\text { Weight } \mathrm{M} \cdot \mathrm{H} \text {. Random. } 95 \% \mathrm{Cl}\end{array}$}} & \multirow{2}{*}{\multicolumn{3}{|c|}{$\begin{array}{c}\text { Risk Ratio } \\
\text { M-H, Random, } 95 \% \mathrm{Cl}\end{array}$}} & \\
\hline & Events & Total & Events & Total & & & & & & \\
\hline Ghai 2014 & 19 & 30 & 24 & 32 & $26.4 \%$ & $0.84[0.60,1.18]$ & & & & \\
\hline Hashemi 2015 & 24 & 32 & 25 & 32 & $41.0 \%$ & $0.96[0.73,1.26]$ & & & & \\
\hline Lee 2009 & 40 & 59 & 22 & 34 & $32.6 \%$ & $1.05[0.77,1.42]$ & & & & \\
\hline Total $(95 \% \mathrm{Cl})$ & & 121 & & 98 & $100.0 \%$ & $0.95[0.80,1.14]$ & & & & \\
\hline Total events & 83 & & 71 & & & & & & & \\
\hline $\begin{array}{l}\text { Heterogeneity. Tau } \\
\text { Test for overall effec }\end{array}$ & $\begin{array}{l}0.00 ; \mathrm{Chi}^{2} \\
\mathrm{Z}=0.52(\mathrm{~F}\end{array}$ & $\begin{array}{l}0.87, d \\
0.60)\end{array}$ & $f=2(P=$ & $.65) ; 1^{2}$ & $=0 \%$ & & 0.5 & $\begin{array}{c}0.7 \\
\text { Interlaminar }\end{array}$ & $1 \frac{1.5}{\text { Transforaminal }}$ & 2 \\
\hline
\end{tabular}

(a) Comparison of pain reduction as relative risk ratio at short term b

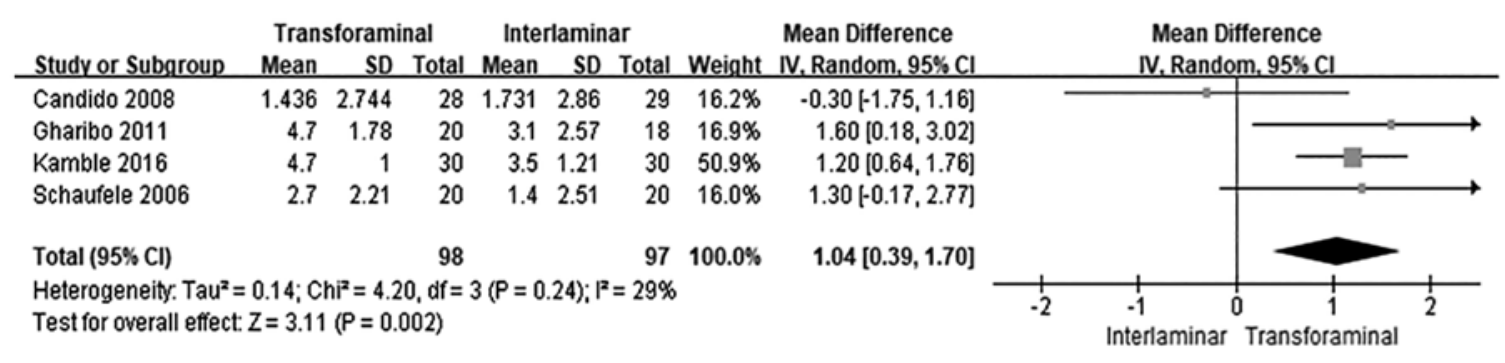

(b) Comparison of pain reduction as mean difference at short term

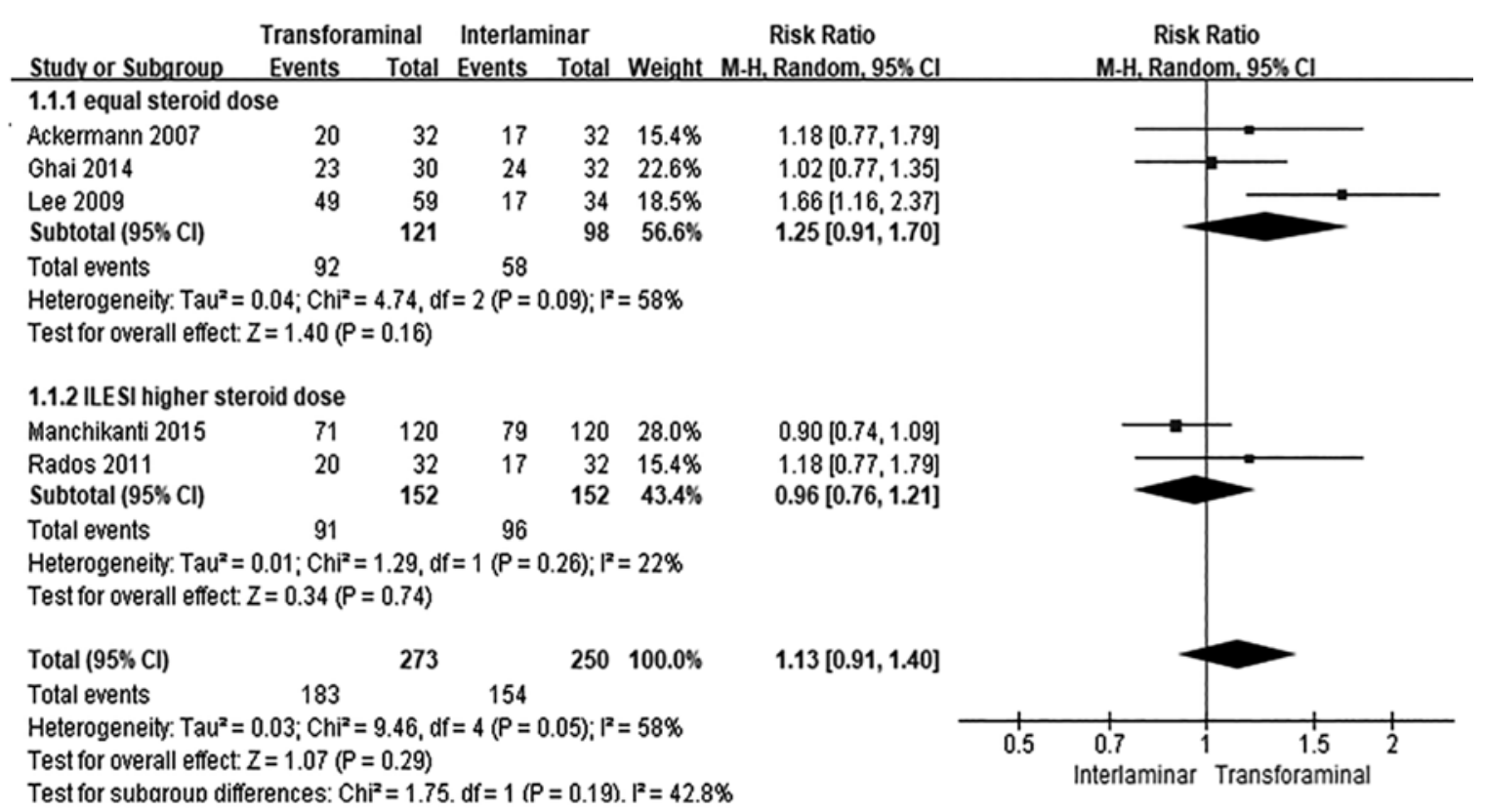

(C) Comparison of pain reduction as relative risk ratio at long term.

Fig. 3. Forest plot of a) comparison of pain reduction as relative risk ratio at short term b) comparison of pain reduction as mean difference at short term c) comparison of pain reduction as relative risk ratio at long term. 
Transforaminal and Interlaminar Epidural Injection

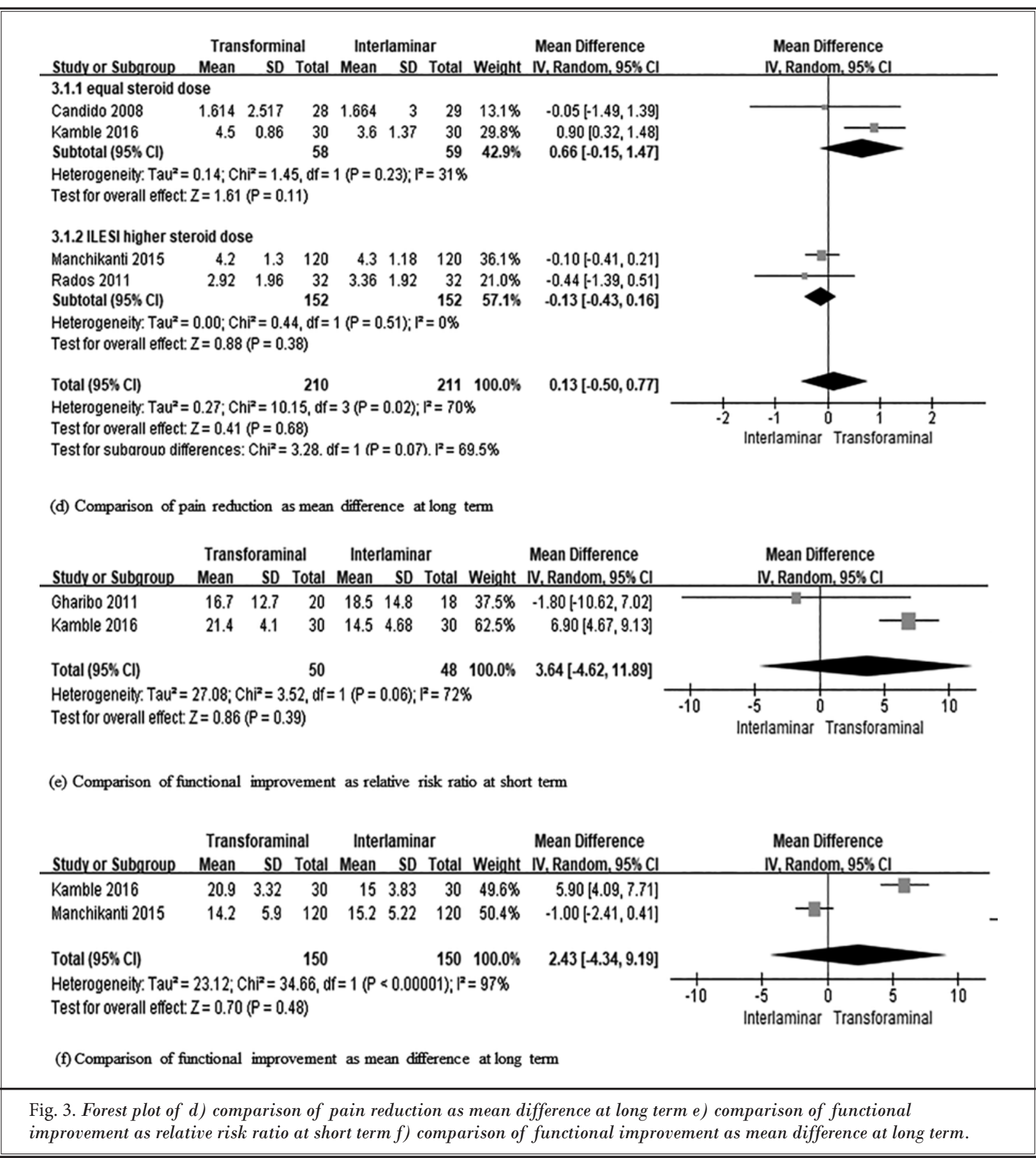

showed contradictory results, the overall mean difference was estimated as $3.64(95 \% \mathrm{Cl}:-4.62-11.89)$, which favored TFEI although without statistical significance $(P$ $=0.39$ ). A high degree of heterogeneity was revealed $(12=72 \%)$, but a subgroup analysis could not be performed because only 2 studies were included (Fig. 3e).

\section{Functional Improvement in the Long-Term Period (4-6 Months)}

Only 2 studies $(14,17)$ were available in the analysis of effect size by the mean difference for functional improvement at 4-6 months after treatment. The estimated overall mean difference was calculated as 2.43 
(95\% Cl: -4.34-9.19), which favored TFEl, but again without statistical significance $(P=0.48)$. The degree of heterogeneity was high $(12=97 \%)$, but the subgroup analysis could not be performed because only 2 studies were included (Fig. 3f).

\section{Level of Evidence and Strength of Recommendation}

The risk of bias was evaluated as low as previously mentioned. Directness was not considered problematic because all included studies directly compared TFEI with ILEI. Publication bias was not assessed because fewer than 10 studies were included in each meta-analysis. However, the level of evidence was considered low due to inconsistency and imprecision. The consistency was considered to have serious problems because some extent of diversity in type of steroid used or treatment protocols existed across studies, and considerable heterogeneity was found in meta-analysis. The degree of precision was also considered serious because most of the studies included fewer than 100 subjects.

All reviewers agreed that TFEI achieved superior clinical outcomes to ILEI as was supported by selected studies with a modest degree. TFEI did not require higher cost, greater resources, or additional devices than ILEI. Thus, TFEl could be applicable to patients with LDH with the same accessibility as ILEI in the clinical setting. However, pain or discomfort occurred more frequently during TFEI than during ILEI due to the needle trajectory approaching near the nerve root $(4,18)$. There was greater concern about serious adverse effects associated with TFEI than ILEI including radicular artery embolism and consequent spinal cord infarction. However, this complication was also related to the steroid type (particulate steroid) that could produce thrombosis after intravasation $(36,37)$. TFEI could be more recommendable than ILEl; however, with low grade evidence due to inconsistency and imprecision of selected studies. The strength of recommendation was determined as weak by discussion of all reviewers.

\section{Discussion}

While TFEI had the advantage of targeting the ventral epidural space which was considered the main source of pain and has been believed to be a more effective method than ILEI $(13-15,28,38)$, conflicting opinions or results also showed that ILEI was not inferior in clinical efficacy and had comparable ability to deliver the medication into the ventral epidural spaces $(16,20,35,39)$. Studies have identified that the propor- tion of ventral epidural spread after ILEI is comparable to that of TFEI $(18,40)$.

A number of concerns have been raised regarding the side effects of TFEI such as lower-limb paraplegia resulting from intravascular penetration or embolic infarct (41). The incidence of pain or discomfort related to nerve root damage and intradiscal penetrations was also higher in TFEI than in ILEl, probably because of the needle approach $(4,18,42)$. Taken together, ILEI could be a suitable alternative to TFEI or the first choice of treatment.

A slightly favorable result toward ILEI was observed in the relative risk ratio in the short-term follow up period, despite no significant difference. This was because that 2 studies $(18,19)$ that supported ILEI used the parasagittal approach, a more lateral approach than the usual ILEI, and thus succeeded in delivering injectate into the lateral and ventral epidural spaces than just using the usual ILEI. In the subgroup analysis for long-term pain control, if ILEI used a higher steroid dose than the usual ILEI, it achieved greater pain reduction, while if it used a dose equal to that of TFEI, TFEI showed greater pain reduction than in the presubgroup analysis of ILEI. This finding suggested that a more lateral approach or higher steroid dose should be required for ILEI to achieve pain control comparable to or slightly better than that for TFEI.

Despite several controversial points and the slight positivity of ILEI observed in some categories mentioned above, the current meta-analysis advocated TFEI because it generally showed trends toward better pain reduction and functional improvement than ILEI in the short term and long term. TFEI obtained significantly greater pain reduction than ILEI in the short term. The deterioration of the superiority of TFEI in the long-term period could be explained by the fact that the efficacy of El was not usually maintained over the long term, so the difference in the clinical efficacy between TFEI and ILEI also diminished over time $(29,43)$. In addition, 6 of the 12 selected studies $(9,14,15,28,30,34)$ including RCTs and non-RCTs were significantly favorable to TFEI, while the rest also demonstrated comparable results between the 2 techniques, but none showed a favorable outcome toward ILEI.

Although ILEI successfully delivered the medication in the ventral epidural space to a degree comparable to that of TFEI, the degree of perineural spread was significantly higher after TFEI than after ILEI (18). Because the radicular pain originated from chemical irritation around the nerve root sheath or dorsal root ganglion, the degree of perineural spread was a key 
factor in effectively reducing radicular pain $(4,44-46)$. This property of TFEI gave it the advantage over ILEI of controlling radicular pain. Most of the studies included in this analysis chose the subjects complaining of radicular leg pain with or without axial back pain. Lee's study (33) distinctively selected the patients with axial back pain without radicular pain and showed no significant difference in mean pain scores between TFEI and ILEI in subjects with LDH. However, interestingly, TFEI achieved significantly better pain control than ILEI in patients with spinal stenosis in that study. This was explained by the fact that a prominent barrier such as a hypertrophied bone or ligament kept the medication from spreading around the nerve root sheath or ventral epidural space in spinal stenosis, whereas this barrier in patients with LDH was not so prominent as in stenosis; thus, posteriorly administered medication spread more easily into the ventral epidural space in cases of LDH (3). This could support the importance of the targeted delivery of medication around the ventral epidural space or nerve root sheath.

The number of injections required for appropriate pain control could be another measurement of treatment effects. One study (47) examining repeat ILEI, showed that $21 \%$ of 120 total participants received only 1 injection, 32\% received 2 injections, and $47 \%$ received 3 injections. Even 56 of 95 patients (59\%) who underwent a second injection required a third injection. Another study examining repeat TFEI showed that only $32.4 \%$ of patients who underwent 2 injections required a third injection to accomplish satisfactory pain reduction (33). This might be because ILEI was less efficient at providing pain relief than TFEI and required an increased number of injections.

Serious adverse effects such as neurologic deficits of the lower limb were concerns related to TFEI (48). An intravascular particulate steroid injection or needle penetration could produce radicular artery occlusions by embolus formation and further cause a spinal cord infarction $(41,49)$. TFEI has been more frequently associated with these adverse effects than ILEI because the former approach positioned the needle closer to the radicular artery (41). But these adverse effects occurred mainly in cases in which particulate steroid was administered, and its replacement with a non-particulate steroid could reduce serious side effects (50-53). A Soluble non-particulate steroid reportedly showed comparable and non-inferior clinical outcomes to those of particulate steroid $(50,54,55)$. Thus injection of soluble nonparticulate steroid could reduce the fear or concerns of serious side effects and consequently prevent unnecessary avoidance of TFEI $(36,37)$.

This study has several limitations. First, few studies have provided data about functional evaluations; thus, meta-analysis for functional improvement analysis was performed with only 2 articles. Although a high degree of heterogeneity was found in this analysis, the subgroup analysis could not be performed. Second, the supportive strength of this study was weak mainly because the level of evidence was low due to inconsistency from diversities across the studies and imprecision induced by the relatively small number of subjects.

\section{Conclusion}

In conclusion, TFEI showed significantly better short-term pain control and modestly favorable outcomes in long-term pain reduction and short- and long-term functional improvement compared with ILEI. However, the evidence level was determined to be low grade. TFEI required no additional cost and resources to ILEI and had equal accessibility or applicability as ILEI. TFEI was preferred to ILEI due to its target specificity, although discomfort during the needle approach more frequently occurred in TFEI. Without the use of particulate steroid, serious side effects could be considerably avoidable. As a result, TFEI could be recommended more frequently than ILEI, but based on low grade evidence, and was weakly recommended.

\section{Acknowledgements}

The authors declare no conflicts of interest or funding sources.

\section{Appendix}

To read appendix, click below:

https://asippfiles.sharefile.com/d-sde852a7b05747a78 


\section{References}

1. Rivera CE. Lumbar epidural steroid injections. Phys Med Rehabil Clin N Am 2018; 29:73-92.

2 Kennedy DJ, Zheng PZ, Smuck M, McCormick ZL, Huynh L, Schneider BJ. A minimum of 5-year follow-up after lumbar transforaminal epidural steroid injections in patients with lumbar radicular pain due to intervertebral disc herniation. Spine ] 2018; 18:29-35.

3 Lee JH, An JH, Lee SH. Comparison of the effectiveness of interlaminar and bilateral transforaminal epidural steroid injections in treatment of patients with lumbosacral disc herniation and spinal stenosis. Clin J Pain 2009; 25:206-210.

4 McLain RF, Kapural L, Mekhail NA. Epidural steroid therapy for back and leg pain: Mechanisms of action and efficacy. Spine J 2005; 5:191-201.

5 Mehta N, Salaria M, Salaria AQ. Comparison of fluoroscopic guided transforaminal epidural injections of steroid and local anaesthetic with conservative management in patients with chronic lumbar radiculopathies. Anesth Essays Res 2017; 11:17-22.

6 Liu J, Zhou H, Lu L, Li X, Jia J, Shi Z, Yao $X$, Wu Q, Feng $S$. The effectiveness of transforaminal versus caudal routes for epidural steroid injections in managing lumbosacral radicular pain: A systematic review and meta-analysis. Medicine (Baltimore) 2016; 95:e3373.

7 Pairuchvej S, Arirachakaran A, Keorochana G, Wattanapaiboon K, Atiprayoon $S$, Phatthanathitikarn $P$, Kongtharvonskul J. The short and midterm outcomes of lumbar transforaminal epidural injection with preganglionic and postganglionic approach in lumbosacral radiculopathy: A systematic review and meta-analysis. Neurosurg Rev 2017.

8 Lutz GE, Vad VB, Wisneski RJ. Fluoroscopic transforaminal lumbar epidural steroids: an outcome study. Arch Phys Med Rehabil 1998; 79:1362-1366.

9 Schaufele MK, Hatch L, Jones W. Interlaminar versus transforaminal epidural injections for the treatment of symptomatic lumbar intervertebral disc herniations. Pain Physician 2006; 9:361-366.

10 Botwin K, Natalicchio J, Brown LA. Epidurography contrast patterns with fluoroscopic guided lumbar transforaminal epidural injections: A prospective evaluation. Pain Physician 2004; 7:211-215.

11 Cooper G, Lutz GE, Boachie-Adjei O,
Lin J. Effectiveness of transforaminal epidural steroid injections in patients with degenerative lumbar scoliotic stenosis and radiculopathy. Pain Physician 2004; 7:311-317.

12 Bhatia A, Flamer D, Shah PS, Cohen SP. Transforaminal epidural steroid injections for treating lumbosacral radicular pain from herniated intervertebral discs: A systematic review and meta-analysis. Anesth Analg 2016; 122:857-870.

13 Ackerman WE, 3rd, Ahmad M. The efficacy of lumbar epidural steroid injections in patients with lumbar disc herniations. Anesth Analg 2007; 104:1217-1222.

14 Kamble PC, Sharma A, Singh V, Natraj B, Devani D, Khapane V. Outcome of single level disc prolapse treated with transforaminal steroid versus epidural steroid versus caudal steroids. Eur Spine ] 2016; 25:217-221.

15 Pandey RA. Efficacy of epidural steroid injection in management of lumbar prolapsed intervertebral disc: A comparison of caudal, transforaminal and interlaminar routes. J Clin Diagn Res 2016; 10:RCo5-11.

16 Chang-Chien GC, Knezevic NN, McCormick Z, Chu SK, Trescot AM, Candido KD. Transforaminal versus interlaminar approaches to epidural steroid injections: A systematic review of comparative studies for lumbosacral radicular pain. Pain Physician 2014; 17:E509-524.

17 Manchikanti L, Singh V, Pampati V, Falco FJ, Hirsch JA. Comparison of the efficacy of caudal, interlaminar, and transforaminal epidural injections in managing lumbar disc herniation: Is one method superior to the other? Korean J Pain 2015; 28:11-21.

18 Ghai B, Bansal D, Kay JP, Vadaje KS, Wig J. Transforaminal versus parasagittal interlaminar epidural steroid injection in low back pain with radicular pain: a randomized, double-blind, active-control trial. Pain Physician 2014; 17:277-290.

19 Hashemi SM, Aryani MR, Momenzadeh S, Razavi SS, Mohseni G, Mohajerani SA, Esmilijah AA. Comparison of transforaminal and parasagittal epidural steroid injections in patients with radicular low back pain. Anesth Pain Med 2015; 5:e26652.

20 Rados I, Sakic K, Fingler M, Kapural L. Efficacy of interlaminar vs transforaminal epidural steroid injection for the treatment of chronic unilateral radicu- lar pain: prospective, randomized study. Pain Med 2011; 12:1316-1321.

21 Manchikanti L, Benyamin RM, Falco FJ, Kaye AD, Hirsch JA. Do epidural injections provide short- and long-term relief for lumbar disc herniation? A systematic review. Clin Orthop Relat Res 2015; 473:1940-1956.

22 Guyatt $\mathrm{GH}$, Oxman AD, Kunz R, Vist GE, Falck-Ytter Y, Schunemann HJ. What is "quality of evidence" and why is it important to clinicians? BMJ 2008; 336:995-998.

23 Manchikanti L, Nampiaparampil DE, Manchikanti KN, Falco FJ, Singh V, Benyamin RM, Kaye AD, Sehgal N, Soin A, Simopoulos TT, Bakshi S, Gharibo CG, Gilligan C), Hirsch JA. Comparison of the efficacy of saline, local anesthetics, and steroids in epidural and facet joint injections for the management of spinal pain: A systematic review of randomized controlled trials. Surg Neurol Int 2015; 6:S194-235.

24 Kaye AD, Manchikanti L, Abdi S, Atluri S, Bakshi S, Benyamin R, Boswell MV, Buenaventura R, Candido KD, Cordner HJ, Datta S, Doulatram G, Gharibo CG, Grami V, Gupta S, Jha S, Kaplan ED, Malla Y, Mann DP, Nampiaparampil DE, Racz G, Raj P, Rana MV, Sharma $M L$, Singh V, Soin A, Staats PS, Vallejo R, Wargo BW, Hirsch JA. Efficacy of epidural injections in managing chronic spinal pain: A best evidence synthesis. Pain Physician 2015; 18:E939-1004.

25 Manchikanti L, Hirsch JA, Cohen SP, Heavner JE, Falco FJ, Diwan S, Boswell MV, Candido KD, Onyewu CO, Zhu J, Sehgal N, Kaye AD, Benyamin RM, Helm S, 2nd, Singh V, Datta S, Abdi S, Christo PJ, Hameed H, Hameed M, Vallejo R, Pampati V, Racz GB, Raj PP. Assessment of methodologic quality of randomized trials of interventional techniques: development of an interventional pain management specific instrument. Pain Physician 2014; 17:E263-290.

26 Manchikanti L, Knezevic NN, Boswell MV, Kaye AD, Hirsch JA. Epidural injections for lumbar radiculopathy and spinal stenosis: A comparative systematic review and meta-analysis. Pain Physician 2016; 19:E365-410.

27 Hjermstad MJ, Fayers PM, Haugen DF, Caraceni A, Hanks GW, Loge JH, Fainsinger R, Aass N, Kaasa S. Studies comparing Numerical Rating Scales, Verbal Rating Scales, and Visual Ana- 
logue Scales for assessment of pain intensity in adults: a systematic literature review. J Pain Symptom Manage 2011; 41:1073-1093.

28 Rezende R, Jacob Junior C, da Silva CK, de Barcellos Zanon I, Cardoso IM, Batista Junior JL. Comparison of the efficacy of transforaminal and interlaminar radicular block techniques for treating lumbar disk hernia. Rev Bras Ortop 2015; 50:220-225.

29 Landa J, Kim Y. Outcomes of interlaminar and transforminal spinal injections. Bull NYU Hosp Jt Dis 2012; 70:6-10.

30 Gharibo CG, Varlotta GP, Rhame EE, Liu EC, Bendo JA, Perloff MD. Interlaminar versus transforaminal epidural steroids for the treatment of subacute lumbar radicular pain: A randomized, blinded, prospective outcome study. Pain Physician 2011; 14:499-511.

31 Candido KD, Raghavendra MS, Chinthagada M, Badiee S, Trepashko DW. A prospective evaluation of iodinated contrast flow patterns with fluoroscopically guided lumbar epidural steroid injections: The lateral parasagittal interlaminar epidural approach versus the transforaminal epidural approach. Anesth Analg 2008; 106:638-644, table of contents.

32 Kawu AA. Epidural steroid injection in patients with lumbosacral radiculopathy in Abuja, Nigeria. J Neurosci Rural Pract 2012; 3:121-125.

33 Lee JH, Lee $\mathrm{SH}$. Can repeat injection provide clinical benefit in patients with lumbosacral diseases when first epidural injection results only in partial response? Pain Physician 2016; 19:E283-290.

34 Ackerman lii WE, Ahmad M. The efficacy of lumbar epidural steroid injections in patients with lumbar disc herniations. Anesth Analges 2007; 104:1217-1222.

35 Ghai B, Vadaje KS, Wig J, Dhillon MS. Lateral parasagittal versus midline interlaminar lumbar epidural steroid injection for management of low back pain with lumbosacral radicular pain: A double-blind, randomized study. Anesth Analg 2013; 117:219-227.

36 Dietrich TJ, Sutter R, Froehlich JM, Pfirrmann CW. Particulate versus non-particulate steroids for lumbar transforami- nal or interlaminar epidural steroid injections: An update. Skeletal Radiol 2015; 44:149-155.

37 El Abd O, Amadera J, Pimentel DC, Gomba L. Immediate and acute adverse effects following transforaminal epidural steroid injections with dexamethasone. Pain Physician 2015; 18:277-286.

38 Vad VB, Bhat AL, Lutz GE, Cammisa F. Transforaminal epidural steroid injections in lumbosacral radiculopathy: A prospective randomized study. Spine 2002; 27:11-16.

39 Kamble PC, Sharma A, Singh V, Natraj $B$, Devani D, Khapane V. Outcome of single level disc prolapse treated with transforaminal steroid versus epidural steroid versus caudal steroids. Eur Spine J 2015.

40 Kim ED, Roh MS, Park JJ, Jo D. Comparison of the ventral epidural spreading in modified interlaminar approach and transforaminal approach: A randomized, double-blind study. Pain Med 2016; 17:1620-1627.

41 Atluri S, Glaser SE, Shah RV, Sudarshan G. Needle position analysis in cases of paralysis from transforaminal epidurals: Consider alternative approaches to traditional technique. Pain Physician 2013; 16:321-334.

42 Levi D, Horn S, Corcoran S. The incidence of intradiscal, intrathecal, and intravascular flow during the performance of retrodiscal (infraneural) approach for lumbar transforaminal epidural steroid injections. Pain Med 2016; 17:1416-1422.

43 Young IA, Hyman GS, Packia-Raj LN, Cole AJ. The use of lumbar epidural/ transforaminal steroids for managing spinal disease. J Am Acad Orthop Surg 2007; 15:228-238.

44 Lee JW, Kim SH, Lee IS, Choi JA, Choi J, Hong SH, Kang HS. Therapeutic effect and outcome predictors of sciatica treated using transforaminal epidural steroid injection. AJR Am J Roentgenol 2006; 187:1427-1431.

45 Jung YS, Suh JH, Kim HY, Min K, Oh Y, Park D, Ryu JS. The Prognostic value of enhanced-mri and fluoroscopic factors for predicting the effects of transforaminal steroid injections on lumbosacral radiating pain. Ann Rehabil Med 2016;
40:1071-1081.

$46 \mathrm{Ng} \mathrm{L}$, Chaudhary N, Sell P. The efficacy of corticosteroids in periradicular infiltration for chronic radicular pain: A randomized, double-blind, controlled trial. Spine (Phila Pa 1976) 2005; 30:857-862.

47 Arden NK, Price C, Reading I, Stubbing J, Hazelgrove J, Dunne C, Michel M, Rogers P, Cooper C. A multicentre randomized controlled trial of epidural corticosteroid injections for sciatica: The WEST study. Rheumatology (Oxford) 2005; 44:1399-1406.

48 Schultz D. Risk of transforaminal epidural injections. Pain Physician 2004; 7:289-290

49 Zhu J, Falco FJ, Formoso F, Onyewu O, Irwin FL. Alternative approach for lumbar transforaminal epidural steroid injections. Pain Physician 2011; 14:331-341.

50 McCormick ZL, Cushman D, Marshall B, Caldwell M, Patel J, Ghannad L, Eng C, Makovitch S, Babu A, Chu SK, Marciniak C, Walega DR, Press J, Plastaras $C$, Kennedy DJ. Pain reduction and repeat injections after transforaminal epidural injection with particulate versus nonparticulate steroid for the treatment of chronic painful lumbosacral radiculopathy. PM R 2016; 8:1039-1045.

51 Glaser SE, Falco F. Paraplegia following a thoracolumbar transforaminal epidural steroid injection. Pain Physician 2005; 8:309-314.

52 Houten JK, Errico TJ. Paraplegia after lumbosacral nerve root block: Report of three cases. Spine ] 2002; 2:70-75.

53 Wybier M, Gaudart S, Petrover D, Houdart E, Laredo JD. Paraplegia complicating selective steroid injections of the lumbar spine. Report of five cases and review of the literature. Eur Radiol 2010; 20:181-189.

54 Mehta P, Syrop I, Singh JR, Kirschner J. Systematic review of the efficacy of particulate versus nonparticulate corticosteroids in epidural injections. PMR 2017; 9:502-512.

55 Feeley IH, Healy EF, Noel J, Kiely PJ, Murphy TM. Particulate and non-particulate steroids in spinal epidurals: A systematic review and meta-analysis. Eur Spine J 2017; 26:336-344. 
